\title{
A study of interactive learning spaces within educational facilities
}

\section{Hoda Gad Al Rab Abdo Madkour}

\author{
Interior Design Department, College of Art and Design, October \\ University for Modern Sciences \& Arts, Egypt
}

\begin{abstract}
Learning takes place in spaces that are not limited to the classroom, as it is a process that occurs everywhere within the educational facility, starting from the classroom to the corridors, roads, etc. The learning spaces within the educational facilities are classified into formal and informal learning spaces. The official learning space is the space that is used according to regular official appointments, and these spaces vary to include classes, lecture halls, laboratories, ceremonies, ... etc. There are several factors that affect the design of formal learning spaces, including: The development in pedagogy: The pedagogy has witnessed a shift towards active learning and collaborative learning, and teaching methods vary according to the need of the scientific subject, which results in arranging the semester according to the teaching method followed. . New students' qualities and habits: Understanding students 'characteristics and habits helps in designing and developing learning spaces. There are five important features for new students that must be taken care of and taken into account: digital, mobile, independence, social, and participatory. Rapid development in educational communication technology: It means all digital and non-digital devices, devices, software and media that are integrated into the education process. Education technologies can be divided into three categories, namely, virtual technologies, installed devices, and mobile devices. The tendency towards the human being at the center of design: through concern for some features, including: health (which includes: physical comfort - good lighting - acoustics indoor air quality), motivation (through attention to sensory signals contact with nature, various color shapes), adaptation ( Through
\end{abstract}


flexibility - sufficient space - portable display - connection to various information - Informal learning space is a space inside the educational facility that allows students to practice and discuss academic work without committing to official deadlines. The spaces that represent informal learning spaces are varied and include: outdoor space, corridors, lobbies and lounges, coffee shop, and library. There are factors that affect the success of informal learning spaces, including: Spaces conform to the needs of learners. Achieving a balance between society and isolation. Stimulus . Availability of technology and ease of contact with information. . Adaptation.

\section{Keywords}

Interactive, Learning Spaces, Educational Facilities, Architecture

\section{Introduction}

A change in design thinking has emerged as a result of an awareness of the environmental effects accompanying modern construction and their impact on humans and the environment. Hence, some new concepts and methods that were not previously familiar in designing and implementing projects, including "sustainable design and green architecture, all reflect the growing interest of Urban sectors address issues of economic development in light of environmental protection, reducing energy consumption, optimal utilization of natural resources, and greater reliance on renewable energy sources. With the advancement of science, the spread of technology and technologies, and the human desire to interact with and acquire them, technology has become an indispensable part of human life. 
Or live without it, so this technology has been directed in a way to achieve adaptation to human requirements, and to provide a suitable internal environment, which is known as smart architecture.

And because the main goal in design is the human being, the concept of interactivity arose as a guide to action resulting from the study of social behavior of pragmatic philosophy, which was concerned with the human experience as a source of knowledge. Modern life generated it, hoping to uncover these problems and work to find appropriate solutions for them. Hence the role of interactive architecture in drawing general lines to see the future in a better way through understanding the situation, studying it and integrating it with technology in order to meet the changing needs of the individual, society and the environment.

The internal space means cutting out a part of the void of the external world with special specifications and determinants that make it suitable for a person to practice different life activities, and these activities and the manner of their performance depend on the nature of thecut part, its size, its design and its relationship to the external public space surrounding it. By it, the architectural body in physical terms is the internal boundaries that define the internal space. Interactivity is one of the features that distinguish one space from another, but what is the interactive space and what are its determinants. 


\section{Research Problem:}

The research problem arises in:

1- The need to design internal spaces that adapt to environmental variables and meet changinghuman needs.

2- The need to design interactive learning spaces that are more flexible and more adaptive to the requirements and needs of the individual, society and the educational process. These spaces are not limited to formal learning spaces only, but rather expand to include informal spaces.

Research methodology: The research uses the descriptive and analytical method in extracting the factors forming the interactive spreads.

\section{Interactive space concept:}

- The interactive space is an environment that interacts with the people in it, as these environments touch the activity of people and interact through various displays: audio, visual, kinesthetic and tactile. - Interactive space is a combination of real space, and real objects with a virtual reality (generated by the computer) instead of produced entirely by computer as in thevirtual reality

The interactive space is an internal space that mutually interacts, responds, or adapts to the human user of the space.

- The interactive space is a space that has the ability to meet changing.

Individual, social and environmental needs, and it is a space that is smart, flexible and adaptive according to the changes occurring on it. 


\section{- Learning Spaces (Informal Learning Spaces:}

Informal learning space is a space inside the educational facility that allows students to practice and discuss academic work without adhering to official dates, and the spread of these spaces varies depending on the type of the educational facility, so schools are limited, for example, to outdoor spaces (outdoor space), where outdoor spaces are used for a wide range From playing and learning opportunities in order to develop children's abilities and give them new experiences, they practice basic learning processes while sitting and walking, such as observation, examination, meditation, data collection and recording, group participation and discussions, in addition to preserving children's health as they are exposed to natural air that helps them focus. As for colleges and universities, they vary. There are informal learning spaces where students spend long periods of their time outside the formal learning spaces (classrooms), so it is important for students to spend this time discussing academic work with their colleagues, so these spaces vary to include internal and external spaces. 


\section{Types of informal learning spaces:}

1- The library: The library space includes a group of books, manuscripts, documents, records, periodicals, general references, publications and other materials that are properly organized.

2- The library within the educational facility aims to serve the objectives of the educational establishment and community service, to provide books, references and other library materials, to allow their lending and photocopy, as well as exchange information by linking the library with other libraries in the world and establishing programs of exchange and cooperation to achieve collective benefit from the resources and books available in these Libraries.

\section{Library spreads can be divided into:}

3-Entrance area: The entrance must accommodate a large number of people and has a security and control area.

4-Student service areas: It includes an information desk, borrowing offices and photo rooms, and it aims to assist students, guide them and provide them with facilities.

5 -The bookshelves area: Students must be given a larger place, so that they can view the books and traffic can be accommodated. 6- Reading, reading and study areas: It is the area designated for the student and includes study cubicles, reading places, places of concentration ... and others. 


\section{Factors that affect the success of informal learning spaces:}

1- The learning spaces are compatible with the needs of the learners: every student has basic requirements, biological (represented in food, beverages, etc.), physiological requirements (lighting, ventilation, etc.), and learning requirements (library, computer, networks, etc.) (...), and equipping the space with good furniture and equipment that are compatible with the needs of the learners works to raise their creative skills towards learning. Judith Heerwagen's research has focused on the existence of four elements that must be present in order to create positive spaces: knowledge effectiveness, social support, psychological factor, and physical factor, as a person's sense of well-being affects production, creativity and participation.

\section{2- Achieving a balance between society and isolation:}

3- The learning spaces need to achieve a balance between the needs of man and society, so learning takes place everywhere, whether it is in a calm (moments of the student's isolation with himself), or in a live (more social) manner, so it must be Learning environments offer a variety of realms that support individual and grouplearning.

4- Motivation: motivating biases attract students and make them respond and love to share with others. Motivation is done through. 
5- Transparency and visual access: The visual link prepares people to be part of something larger, and the link between formal and informal learning spaces such as classes in lobbies, halls or corridors has become part of the learning experience and that through advocacy in which learning activities.

6- Surprise: Ambiguity and surprise stimulate the human mind and the senses and invite discovery, so consider the possibility of corridors and paths that provide unexpected spaces for group work, or hide away for quiet individual work, all of which are interactions that help students exchange and ignite new contacts and unexpected activities.

7- Contact with nature: Nature works on continuous stimulation for students because of the change in the elements, so the formation of learning spaces that exist in the open air (outdoor spaces) is important and that provides students with a sense of security and pleasure, and simulating nature also achieves student satisfaction.

8 - Availability of technology and ease of contact with information: the presence of appropriate technology within the space works to attract students and practice individual and group activities, as well as access to information and research, and network connectivity attracts students to use mobile devices for research and work, and others.

9- Adaptation: The adaptive space supports activities and provides students with freedom in designing learning activities, so the presence of movable furniture units is more flexible and helps to adapt. 


\section{Results:}

\section{It boils down to a number of important points:}

1- Educational facilities are affected by changes in important factors such as population change, cultural, social, political and environmental change, technological change, etc., and educational buildings must keep pace with such changes to be more effective. 2- The learning space is one of the most important spaces within the educational establishment and affects positively or negatively on the educational process and on students as well as lecturers. Therefore, attention was given to that space and was classified into formal and informal learning spaces.

3- Among the factors that affect the success of informal learning spaces, including: compatibility of spaces with the needs of learners, achieving balance between society and isolation, motivation, availability of technology, ease of communication with information, adaptation.

4- Considering informal learning spaces as an integral part of the educational process.

\section{Recommendations:}

The study recommends the following:

1- Developing the design of learning spaces within educational facilities and considering them an integral part of the school curriculum, and moving towards dynamic design within the learning space through the use of moving elements that can be modified, changed and transformed within the space to be more adaptive to users and their requirements and be able to adapt to modern educational systems and develop educational subjects. 
2- Keeping pace with the development in the outside world, in terms of materials, technology, techniques and modern trends in design, and subjecting it to what suits the requirements of the individual and society. - The number of students is proportional to the size and nature of the place, so that every student gets his ideal share of the space.

3- I recommend to researchers in this field to complete the study and try to find other design solutions that achieve interactivity and accommodate a larger number of students; I also recommend studying the requirements of faculty members (teachers), about their needs for the place and knowing the teaching strategies used by them, to reach the best design solutions.

\section{References}

1- Najwan Shehata - Nanotechnology and its Impact on the Development of Interactive InteriorDesign - Published Research Third Conference 2007 Visual Arts between - Variable and Static.

2- Saeed Ahmed Hassan: University Library, Dar Jabal - Beirut - First Edition 1992.

3- Rudd, Tim, Reimagining Outdoor Learning Spaces (primary capital, Co-design and education transformation), futurelab handbook, 2008, publications.becta.org.uk.

4- Gamals, Ahmed, Engaging \& retaining students using cutting-edge Technologies ( Design of the Outdoor, classroom \& Electronic Learning Spaces), International HETL conference, Orlando, Florida, January 13-5-2013. 
5- Oblinger, Diana G, Learning spaces, e-book, educase, 2006, www.educase.edu/learning space.04-01-2015.

6- Judith H. Heerwagen, "Design, Productivity, and Well-Being: What Are the Links?" paper presented at the American Institute of Architects Conference on Highly Effective Facilities, March 1998, Cincinnati, Ohio.

7- Mohanad Ali Mohamed Fouda, The Influence Of The Architectural Styles Of The Mediterranean Countries On The Heritage Building' Styles At The City Of Mansoura, Egypt, International Journal of Architectural Engineering and Urban Research, Vol. 2, No. 2, 2019, pp. 19-22.

8- Mohamed Mohi Eldin Mahmoud, Water Fountains In The Islamic Architecture: Simplicity Of Techniques \& Fascinating Performance, International Journal of Architectural Engineering and Urban Research, Vol. 2, No. 2, 2019, pp. 34-39.

Received: May 2020

Accepted: June 2020 